\title{
MicroscopyPioneers
}

\section{Pioneers in Optics: James Gregory and Warren de la Rue}

\author{
Michael W. Davidson \\ National High Magnetic Field Laboratory, Florida State University, Tallahassee, FL 32306 \\ davidson@magnet.fsu.edu
}

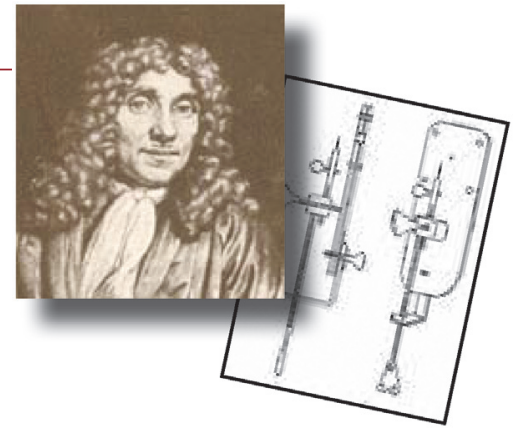

\section{James Gregory \\ (1638-1675)}

James Gregory was a seventeenth-century mathematician and astronomer who developed infinite series representations for various trigonometric functions but is better known for providing the first account of a practical reflecting telescope. Born in Drumoak, Scotland, Gregory was the sickly son of a clergyman and was first educated by his mother. She introduced him to a number of advanced subjects at an early age, including elementary mathematics and geometry. Following his father's death in 1650 , Gregory was sent to grammar school and then attended Marischal College in Aberdeen, where he focused his studies on astronomy and mathematical optics.

After graduating in 1657, Gregory wrote The Advance of Optics, which discussed such topics as lenses, mirrors, reflection, refraction, parallax, and transits. The work also introduced the use of photometric methods to estimate the distances of stars, but its most notable inclusion was the description of a reflecting telescope. The instrument, now known as the Gregorian telescope, used a secondary concave mirror to collect the reflection from a primary parabolic mirror and refocus the image back through a tiny hole in the primary mirror to an eyepiece. Gregory argued the advantages of such a design, but his depiction was purely theoretical because he did not have the instrument-making skill required to materialize his idea.

Gregory journeyed to London in 1662, where he secured a publisher for The Advance of Optics. The work was released in 1663 , and Gregory began seeking someone with the ability to fabricate his reflecting telescope. However, his quest was largely unsuccessful, and the completion of a functional Gregorian telescope was left for others to achieve. Gregory then redirected his energies, deciding in 1664 to resume his scientific studies in Padua, Italy.
During his stay in Italy, Gregory completed two insightful mathematical treatises, The True Squaring of the Circle and Hyperbola and The Universal Part of Geometry. Based on his new works, Gregory found a certain amount of triumph waiting for him upon his return to London in 1668. He was elected to the Royal Society and was offered a position at the University of St. Andrews. He relocated to Scotland in order to accept the professorship and soon married a young widow. There he remained for several years, teaching, studying, and beginning his own family.

Gregory was hesitant to publish during this time because of controversy surrounding his earlier works. Christiaan Huygens had implied in a review of The True Squaring of the Circle and of Hyperbola that he had been the first to prove some of the findings it held. Not wanting to precipitate similar problems with other scientists, Gregory withheld many of his mathematical methods from the public, though he shared them among friends in correspondence. Consequently, he received only a fraction of the credit he deserved during his lifetime, the magnitude of his achievements only becoming recognized in the 1930s when his papers were examined and published by H. W. Turnbull.

In 1674, Gregory left the University of St. Andrews amid increasing pressure from the school's governing board and other faculty members. Blaming Gregory for interfering with the students' acceptance of the classical curriculum of St. Andrews, they treated him as an outcast and eventually withheld his pay. Pleased to be offered an alternative, Gregory accepted a chairmanship of mathematics at the University of Edinburgh. Unfortunately, less than a year into his new appointment, Gregory suffered a blinding stroke while observing Jupiter through a telescope. He died only a few days later in October of 1675, only thirty-six years old.

\section{Warren de la Rue}

(1815-1889)

Warren de la Rue was a nineteenth-century microscopist, astronomer, and chemist who invented an instrument for observing the sun, known as the photoheliograph. The son of a prominent businessman in the stationery industry, de la Rue was born in Guernsey on January 15, 1815, and was educated in Paris. Upon graduation, he accepted a position at his father's firm and in 1851 invented a machine that made envelopes. However, science was his real passion, and he carried out experiments and research during his spare time. 
De la Rue's studies were broad and he published papers on a number of different topics. His investigations of photoactive chemicals, electrical discharge in gaseous substances, and batteries are especially notable, the last resulting in the invention of the silver chloride cell. De la Rue was also intrigued by optics and carried out many experiments in the field, some of which tested the wave theory of light. $\mathrm{He}$ is most remembered, however, for his pioneering role in astrophotography. His adaptation of the wet-plate process to the

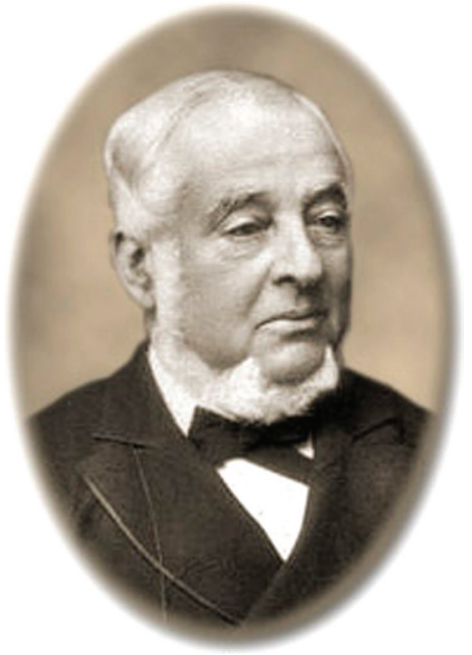
photography of the moon in the early 1850 s allowed for highly improved images of the lunar body, which were unsurpassed in their detail for many years. Early success in his astronomical ventures led de la Rue to establish a new English observatory in Cranford, Middlesex, and in 1854, he was approached by the overseers of the renowned Kew Observatory who were seeking a way to produce daily photographs of the sun, a project originally proposed by John Herschel. De la Rue designed a special telescope for the project dubbed the photoheliograph.

The initial photoheliograph designed by de la Rue was built under his supervision by Andrew Ross and Company. The instrument, which was equipped with an achromatic objective and a Huygenian eyepiece, produced images about four inches in diameter. De la Rue's photoheliograph was installed at Kew in 1858, though several years would pass before many of the small technical difficulties associated with

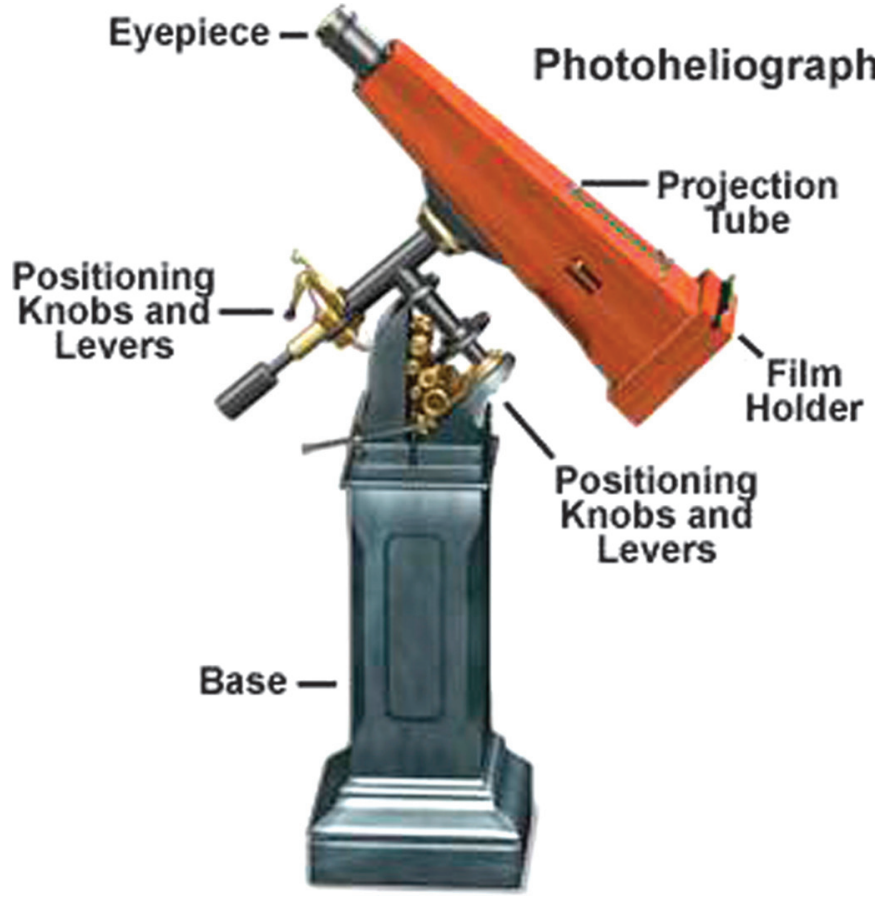

the instrument were overcome. Photographs of the sun were obtained with the photoheliograph at Kew on almost every sunny day for more than a decade, at which time the device was moved to the Royal Observatory at Greenwich, where regular solar photography was carried out until 1882. De la Rue published some of the findings from his own observations with the photoheliograph in Researches on Solar Physics (1865-68). Notably included in the work is de la Rue's account of an expedition to Spain in 1860, which he undertook in order to photograph a total eclipse of the sun that occurred on July 18. The images produced during that trip were the first to definitively demonstrate that the corona seen around the moon during a solar eclipse is a phenomenon associated with the sun rather than the moon.

De la Rue retired from active astronomy in 1873, but before that time he had discovered more than 500 nebulae. Most of the many instruments he had accumulated over the years were donated to the observatory at Oxford University. On April 19, 1889, de la Rue died in London. Still, his pioneering work had paved the way for many future astronomers, and his many contributions to science were widely acknowledged during his lifetime. A member of the Royal Society of London and the Royal Astronomical Society, de la Rue received the highest honors bestowed by both associations, the Royal Medal (1864) and the Gold Medal (1862), respectively. He was also a member of the Chemical Society, of which he was elected president twice, and the prestigious French Academy of Sciences. The original de la Rue photoheliograph is retained at the Science Museum of London.

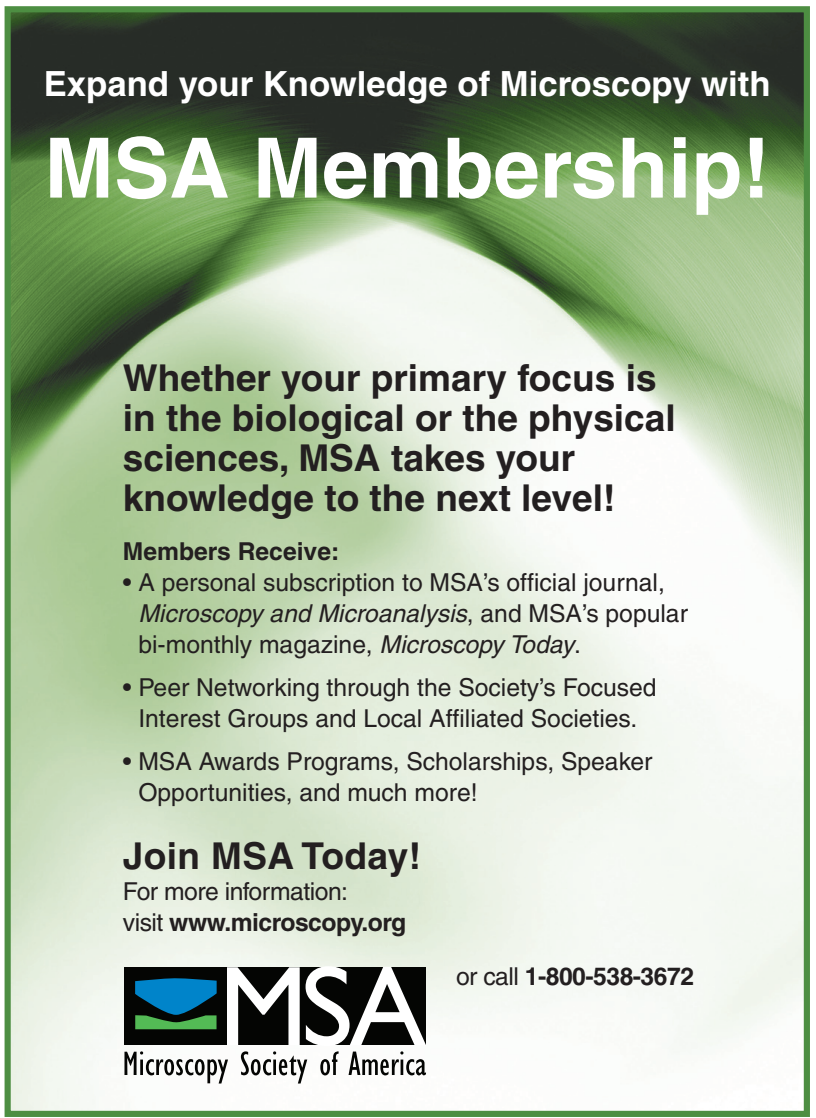

